
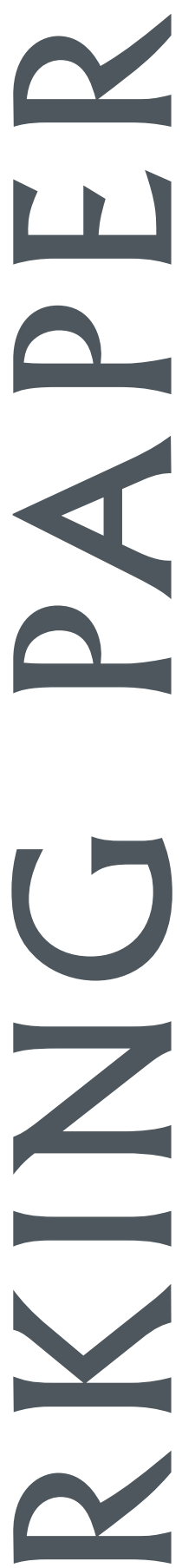

EAST-WEST CENTER 
The U.S. Congress established the East-West Center in 1960 to foster mutual understanding and cooperation among the governments and peoples of the Asia Pacific region including the United States. Funding for the Center comes from the U.S. government with additional support provided by private agencies, individuals, corporations, and Asian and Pacific governments.

East-West Center Working Papers are circulated for comment and to inform interested colleagues about work in progress at the Center.

For more information about the Center or to order publications, contact:

Publication Sales Office

East-West Center

1601 East-West Road

Honolulu, Hawaii 96848-1601

Telephone: 808-944-7145

Facsimile: 808-944-7376

Email: ewcbooks@EastWestCenter.org

Website: www.EastWestCenter.org 


\section{兲 EAST-WEST CENERR}

\author{
Environmental Change, Vulnerability, and Governance Series
}

No. 60, May 2004

\section{The World Bank's Prototype Carbon Fund and China}

\author{
ZhongXiang Zhang
}

ZhongXiang Zhang is a Fellow in the Research Program at the East-West Center. He is also an adjunct professor of economics at both the Chinese Academy of Social Sciences and Peking University, Beijing, and an affiliate professor of economics at the University of Hawaii at Manoa. As the author of more than 120 publications in the fields of energy, climate and environmental economics, trade and the environment, public finance and macroeconomic modelling, he wrote the book The Economics of Energy Policy in China: Implications for Global Climate Change (Edward Elgar, 1998) and co-authored International Rules for Greenhouse Gas Emissions Trading (United Nations, 1999). Currently, he is serving on the editorial boards of seven international journals and one Chinese journal. He also served as an expert/consultant to many national and international organizations, served on many high level panels, presented research findings in more than 25 countries over the past six years, and has been included in Marquis Who's Who in Science and Engineering, Who's Who in the World, and Who's Who in America.

East-West Center Working Papers: Environmental Change, Vulnerability, and Governance Series is an unreviewed and unedited prepublication series reporting on research in progress. The views expressed are those of the authors and not necessarily those of the Center. Please direct orders and requests to the East-West Center's Publication Sales Office. The price for Working Papers is $\$ 3.00$ each plus shipping and handling. 


\title{
The World Bank's Prototype Carbon Fund and China
}

\author{
ZhongXiang Zhang \\ Research Program \\ East-West Center \\ 1601 East-West Road \\ Honolulu, HI 96848-1601 \\ USA \\ Tel: +1 8089447265 \\ Fax: +1 8089447298 \\ Email: ZhangZ@EastWestCenter.org
}




\begin{abstract}
As the first global carbon fund, the World Bank's Prototype Carbon Fund (PCF) aims to catalyze the market for project-based greenhouse gas emission reductions while promoting sustainable development and offering a learning-by-doing opportunity to its stakeholders. Since the inception in 2000, the PCF has engaged in a dialogue with China to get it to sign up as a host country, because the World Bank and other international and bilateral donors expect great potential of the clean development mechanism (CDM) in China and feel the significant need for building CDM capacity in China to enable it to gain more insight into the CDM and increase its capacity to initiate and undertake CDM projects. This paper first discusses why China had hesitated to sign up as a host country of PCF projects until late 2003. Then the paper explains what has led China to endorse the PCF projects. The paper ends with discussions on the implications of the PCF's offering prices for the emerging global carbon market.
\end{abstract}

JEL classification: Q54; Q58; Q52; Q48

Keywords: Carbon prices; Carbon market; China; Prototype Carbon Fund; The World Bank 


\section{Introduction}

In recognition of the potential impacts of climate change on its borrowing client countries, the World Bank has been participating in the climate change process since its beginning. This, combined with the limited existing capacity in developing countries and in economies in transition in originating CDM and joint implementation (JI) projects, led the World Bank to undertake a pioneering role in developing the market for greenhouse gas emission reductions through the establishment of the Prototype Carbon Fund (PCF, 2003). As the first global carbon fund, the PCF aimed to:

- demonstrate how project-based transactions in greenhouse gas emission reductions can contribute to the sustainable development of developing countries and countries with economies in transition;

- share the knowledge gained in the course of the PCF's operations with all interested parties; and

- demonstrate how the World Bank can work in partnership with the public and private sectors to mobilize new resources for its borrowing member countries while addressing global environmental concerns. ${ }^{1}$

The PCF operates like a mutual fund, pooling the collective resources from 23 investors (6 governments and 17 companies) and investing these funds in projects that reduce greenhouse gas emissions or remove these emissions from the atmosphere and that would in many cases not be financially viable without financial support from the PCF. The PCF is not legally able to own these carbon credits generated from the PCF projects. These

\footnotetext{
${ }^{1}$ See the PCF web site at: http://carbonfinance.org.
} 
credits have to go back to those investors pro rata according to their level of investment in the Fund. Participants in the Fund agreed on a set of project selection and portfolio development criteria designed to serve the "learning-by-doing" objective of the PCF while reducing project risk through portfolio diversity. In practice, these objectives are achieved by balancing the Fund's portfolio between: $\mathrm{CDM}$ and $\mathrm{JI} ;{ }^{2}$ geographic regions; and eligible sectors and technologies and/or fuel switching in projects that create emissions reductions additional to a credible baseline of what would have happened without the CDM/JI project.

The World Bank and other international and bilateral donors are keen to support CDM capacity building in China because they expect great potential of the CDM in China and feel the significant need for China to gain more insight into the CDM and increase its capacity to initiate and undertake CDM projects. Thus, since the inception, the PCF has engaged in a dialogue with China to get it to sign up as a host country. This paper first discusses why China had hesitated to sign up as a host country of PCF projects until late 2003. Then the paper explains what has led China to endorse the PCF projects in the end. The paper ends with discussions on the implications of the PCF's offering prices for the emerging global carbon market.

\section{Why had China hesitated to sign up as a host country?}

With the already huge and growing amount of greenhouse gas emissions and a great deal of low-cost abatement options available, China is widely regarded as the world's number

\footnotetext{
${ }^{2}$ In February 2001, the PCF decided that it would seek a ratio of 3 to 2 between CDM and JI projects in the portfolio (PCF, 2003).
} 
one host country of CDM projects (Zhang, 1999, 2000, 2001). But, making this potential a reality represents a significant challenge for China, because there has been a general lack of awareness by both the Chinese government and business communities, institutional structure, and implementation strategy. This has raised great concern about China's ability to compete internationally for CDM projects and fully exploit the potential. The World Bank and other international and bilateral donors feel the significant need for CDM capacity building in China to enable it to gain more insight into the CDM and increase its capacity to initiate and undertake CDM projects. For this, since the inception, the PCF has engaged in a dialogue with China to get it to sign up as a host country. The PCF experience suggests that completing the first carbon deal in a host country is a powerful capacity building tool, with tremendous impact on supply on its own (Lecocq, 2003). But China had hesitated to sign up the PCF until late 2003. There are several reasons. First, rules governing the $\mathrm{CDM}$ are not agreed on among parties to the Kyoto Protocol until the seventh Conference of the Parties to the United Nations Framework Convention on Climate Change (UNFCCC), and as a very important player, China does not want to see that its involvement in the PCF leads the rules operating the PCF to have any impacts on overall rule-setting for the Kyoto mechanisms. Second, China considers the PCF's targeted price levels of about US\$ 3.3 per ton of $\mathrm{CO}_{2^{-}}$ equivalent too low, ${ }^{3}$ relative to its expectation of US\$ 10 per ton of $\mathrm{CO}_{2}$-equivalent. ${ }^{4}$ Understandably, the investors in the PCF demand a low price. The current host countries

\footnotetext{
${ }^{3}$ Minimum requirements for PCF projects specify that estimated cost of emission reductions should preferably be less than US\$ 10 per ton of carbon, which is equivalent to about US\$ 3 per ton of $\mathrm{CO}_{2}$-equivalent (see the PCF web site at http://carbonfinance.org).

${ }^{4}$ Author' interviews in Beijing, January 2004.
} 
of the PCF projects have no serious demand to increase the PCF's price levels. China is the only country that seriously regards the PCF's price levels as too low, and views that the low price levels will affect the sustainability and expansion of the PCF over the long run. ${ }^{5}$ Third, the PCF establishes a practice where the host country takes the risk in case a project does not perform as planned, and China does not accept that the PCF projects do not bear some risks in implementation and crediting, although the PCF guarantees payment on delivery of the certified emissions reductions (CERs). ${ }^{6}$ Fourth, there are some concerns about the formal status of PCF projects regarding whether they can eventually be recognized as CDM projects. ${ }^{7}$

\section{What led China to endorse the PCF projects?}

Despite the difference in opinion, negotiations between the PCF and China have never stopped. Two sides have made important progress in negotiations recently, and China has determined to be a host country of the PCF. At this moment, two PCF projects in China

\footnotetext{
${ }^{5}$ Author' interviews in Beijing, January 2004.

${ }^{6}$ The risk of non-delivery for the PCF, a carbon buyer, is mitigated by purchasing CERs on delivery rather than upfront. Although a project developer is able to use this carbon purchase agreement as a collateral to leverage financing that would otherwise not have been available, the host country and business's risks associated with the underlying project remain, unless the carbon buyer is able to share these risks with the project developer (Lecocq, 2003). In general, PCF transactions are structured so that the project sponsors and their creditors assume most project risks, while the PCF bears most of the Kyoto Protocol-related risks (PCF, 2003).

${ }^{7}$ To be recognized as CDM projects, the baseline methodologies of the PCF projects have to be approved by the CDM Executive Board (EB). To date, the CDM EB has approved a total of nine methodologies. Two PCF methodologies get approved among the eight submissions (JIQ, 2004). At this point, it is difficult to predict which portion of the PCF portfolio would eventually be covered by approved methodologies. But the bottom line is that as more methodologies get approved, the regulatory uncertainty regarding the status of the PCF projects will further diminish.
} 
are under preparation: one on run-of-river hydropower to displace coal-fired power in Gansu Province, and another on coal bed methane capture and power generation in Shanxi Province. The PCF will invest US\$ 8.5 million in the hydropower project and receive the emissions reduction of 2 million tons of $\mathrm{CO}_{2}$-equivalent of the total project's emissions reduction of 3.7 million tons of $\mathrm{CO}_{2}$-equivalent (PCF, 2003). Although the PCF has informally promised to offer the most favourable price, ${ }^{8}$ no agreement has been made on the purchasing prices of emissions reductions for the PCF project. For the coal bed methane project, the PCF as one of the investors will contribute US\$12.75 million in return of 3 million tons of $\mathrm{CO}_{2}$-equivalent of the total project's emissions reduction of 29 million tons of $\mathrm{CO}_{2}$-equivalent (PCF, 2003).

What led the PCF to reach a watershed agreement with China that leads it to endorse the PCF projects? First, it is related to the time table set for the funds reserved for projects in China. At the creation of the PCF, its Participants Committee has decided to reserve some funds for potential projects in China. But these funds are only able to be reserved by the end of 2003. While China still views that the PCF projects do bear some risks in implementation and crediting, such perceived risks are not at unreasonable levels because the PCF guarantees payment on delivery of the CERs.

\footnotetext{
${ }^{8}$ For each PCF project, a fixed price is agreed through the negotiations between the PCF and the project developers. This way to share the price risk provides incentives for both parties to perform. Some PCF contracts provide the project developers the opportunity to sell a fixed volume of the annual emissions reductions, which are generated above the amount due to the PCF, to a third party (PCF, 2003). Alternatively, under the Dutch CERUPT (Certified Emission Reduction Unit Procurement Tender) program, the contractor must offer the surplus of generated CERs to Senter (the tendering authority for the CERUPT) at the market price of the CERs at the time of delivery before it can do so to any other party, although Senter is in no way obligated to purchase more CERs than are agreed upon in the contract (Senter Internationaal, 2001).
} 
Another reason is related to weak demand for CERs, which makes it much hard for China to negotiate with the PCF on the price. It is conceivable that China's side is keen to ensure that the carbon credits from China have a high value. However, as shown in Table 1 indicating the current price levels for CDM projects at less than US\$ 6 per ton of $\mathrm{CO}_{2^{-}}$ equivalent, the current development of the carbon market just turns the price of carbon credits the other way around, and leaves China a very little space to influence the market. ${ }^{9}$

\section{Table 1 Prices of carbon credits under the selected programs}

\begin{tabular}{l|c}
\hline Programs & $\begin{array}{l}\text { Price of carbon credits (US\$ per ton of } \\
\mathrm{CO}_{2} \text {-equivalent) }\end{array}$ \\
\hline World Bank's Prototype Carbon Fund & $3-4$ \\
Dutch CERUPT program & $4.4-5.5^{*}$ \\
Dutch-IFC CDM Facility & $\sim 4$ \\
Dutch-IBRD CDM Facility & $\sim 4$ \\
\hline
\end{tabular}

$* € 4-5$ per ton of $\mathrm{CO}_{2}$-equivalent.

Source: Zhang (2004).

Third, China hopes to use those projects on the margin to gain much-needed, real learning. Recongnising that it is hard to change the situation in weak demand in the short run, China thought that it is whorthwhile undertaking some PCF projects, in particular those PCF projects that fall into the priority area under the CDM in China and whose local developers are determined to undertake these projects and need the funding on the margin. In this case, the funding from the PCF is considered additional. Undertaking

\footnotetext{
${ }^{9}$ On the other hand, China is fully aware of its role as a dominated suppler of CERs. Whatever prices are set for China projects will have impacts on the world prices. Thus, China is not to give up the price issue so easily.
} 
these projects will provide much-needed, real learning about baseline setting, project boundaries, monitoring and verification at project levels, these aspects that are most relevant to all prospective projects under the CDM but in which China has gained little experience in the AIJ (Activities Implemented Jointly) pilot phase. ${ }^{10}$

Table 2 The registered AIJ projects in China

\begin{tabular}{|c|c|c|c|c|c|}
\hline Project & Type $^{\mathrm{a}}$ & $\begin{array}{l}\text { Parties } \\
\text { involved } \\
\text { (host/investor) }\end{array}$ & $\begin{array}{l}\text { Lifetime } \\
\text { (years) }\end{array}$ & $\begin{array}{l}\text { Emissions } \\
\text { reductions per } \\
\text { year (tons of } \\
\mathrm{CO}_{2} \text {-equivalent) }\end{array}$ & $\begin{array}{l}\text { Unit abatement } \\
\text { cost (US\$ per } \\
\text { avoided ton of } \\
\mathrm{CO}_{2^{-}} \\
\text {equivalent) }\end{array}$ \\
\hline $\begin{array}{l}\text { A. Installation of a } \\
\text { coke dry-quenching } \\
\text { facility }\end{array}$ & $\begin{array}{l}\text { Energy } \\
\text { efficiency }\end{array}$ & China/Japan & 20 & 68265 & 19.6 \\
\hline $\begin{array}{l}\text { B. Model project for } \\
\text { energy conservation } \\
\text { in electric furnace } \\
\text { used for ferro-alloy } \\
\text { refining }\end{array}$ & $\begin{array}{l}\text { Energy } \\
\text { efficiency }\end{array}$ & China/Japan & 20 & 29050 & 22.6 \\
\hline $\begin{array}{l}\text { C. CFBC \& CHP } \\
\text { project in Shangqiu } \\
\text { thermal power plant } \\
\text { in Henan Province of } \\
\text { China }\end{array}$ & $\begin{array}{l}\text { Energy } \\
\text { efficiency }\end{array}$ & China/Norway & 20 & 87480 & 15.0 \\
\hline $\begin{array}{l}\text { D. Model project for } \\
\text { utilization of waste } \\
\text { heat from } \\
\text { incineration of refuse } \\
\text { in Harbin of China }\end{array}$ & $\begin{array}{l}\text { Fugitive } \\
\text { gas capture }\end{array}$ & China/Japan & 20 & 62896 & 31.1 \\
\hline
\end{tabular}

${ }^{a}$ The Intergovernmental Panel on Climate Change has classified type of AIJ project as energy efficiency; renewable energy; fuel switching; forest preservation, restoration or reforestation; afforestation; fugitive gas capture; industrial process; solvents; agriculture; waste disposal; or bunker fuels.

Source: Zhang (2004).

\footnotetext{
${ }^{10}$ The different attitudes towards the AIJ pilot phase among the Chinese ministries concerned at the beginning put China at the slow starter of AIJ projects. As a result, China has only hosted 5 AIJ projects, with 4 projects registered with the UNFCCC Secretariat (see Table 2). For all these projects, there have been quite tough bilateral negotiations between China and the investor countries. The unit costs of abatement for these registered projects are very high.
} 


\section{The implications of the PCF's offering prices}

When applauding this positive development in the PCF, we have to realize that host countries like China are very concerned about the price issue. The World Bank and the Dutch government are the two most active players on the buyer side in project-based transactions. In volume terms, they represent $30 \%$ and $26 \%$ of the carbon market in $2002-$ 2003, respectively, as shown in Figure $1 .{ }^{11}$ Currently, the PCF pays between US $\$ 3.5$ and US\$ 4.0 per ton of $\mathrm{CO}_{2}$-equivalent, and this price range was set in 1999 at the creation of the PCF. ${ }^{12}$ The Dutch CERUPT program is aiming at price levels of about US\$ 5 per ton of $\mathrm{CO}_{2}$-equivalent. The offering price of the PCF is not intended to serve as the market price. Given its dominated role on the buyer side, however, it will largely in practice set the standard for the carbon market. Private investors are unlikely to accept projects with a higher cost. ${ }^{13}$ This raises a very important question of striking the balance between encouraging investors to engage CDM projects (thus increasing the volume of CERs of CDM projects) and ensuring the quality of CERs. If the unit cost of abatement is so high, potential investors are scared away. Without CDM investment, there is no delivery of CERs. On the other hand, government and multinational actors have so far totally

\footnotetext{
${ }^{11}$ As shown in Figure 1, the share of Japan in the carbon market increased from 6\% in $2001-2002$ to $23 \%$ in $2002-2003$. Unlike the Netherlands, Japan's purchases are mainly from private entities.

${ }^{12}$ Cited in the Report of the Asia Meeting on Efficient Clean Development Mechanism Operations, organised by the UNDP and the World Bank, 1-3 April 2003, Kuala Lumpur, Malaysia.

${ }^{13}$ To avoid harming their negotiation positions either in subsequent deals or in negotiating with the government on the emissions target and policy, private players often keep key elements of their deals such as prices or contract features confidential. However, given the fact that the publicly disclosed offering prices of PCF projects provide information on abatement costs in both economies in transition and in developing countries, it is conceivable that private players are unwilling to go beyond this price bound.
} 
dominated on the demand side for CDM projects. If they are just interested in getting cheap CERs, there will be no strong incentives to encourage potential investors to develop CDM projects, in particular those sustainable projects like renewable energy projects. After all, the PCF experience shows that, at the carbon price of US\$ 3 per ton of $\mathrm{CO}_{2}$-equivalent, carbon finance can hardly increase the internal rate of return of many project types by more than $5 \%$, except for landfill gas (LFG) capture project ${ }^{14}$ (See Table 3). Thus, the corresponding CERs stream is rarely the decisive factor that makes the most significant difference and renders these projects viable.

Table 3 Impact of carbon finance on project financing

\begin{tabular}{l|c}
\hline Technology & $\begin{array}{l}\text { Increases in project internal rate of return } \\
\text { with carbon credits priced at US\$ 3 per ton } \\
\text { of } \mathrm{CO}_{2} \text {-equivalent (\%) }\end{array}$ \\
\hline Hydro & $0.8-2.6$ \\
Wind & $1.0-1.3$ \\
Bagasse & $0.4-3.6$ \\
Energy efficiency/district heating & 2.0 \\
Gas flare reduction & $2.0-4.0$ \\
Biomass & $2.0-7.0$ \\
Municipal solid waste & $>5$ \\
\hline
\end{tabular}

Source: PCF (2002).

\footnotetext{
${ }^{14}$ The 100-year global warming potential of methane is 23 times that of $\mathrm{CO}_{2}$, implying that abating one ton of methane emissions is equivalent to 23 tons of $\mathrm{CO}_{2}$ emissions abated. Thus, projects involving a reduction in methane emissions are much more costeffective than projects aimed at reducing $\mathrm{CO}_{2}$ emissions. For LFG to power generation projects, carbon finance can contribute up to 1.5 cents per $\mathrm{kWh}$ to the project and can boost the project internal rate of return by $5 \%$ or more. But at the carbon price of US\$ 3 per ton of $\mathrm{CO}_{2}$-equivalent, carbon finance can only contribute to $0.15-0.50$ cents per $\mathrm{kWh}$ for conventional renewable energy projects (PCF, 2002). This explains why LFG capture project takes the lead among all project types. As shown in Figure 2, this type of project accounts for $30 \%$ of the total volume of project-based emission reductions transacted in 2002-2003.
} 
Figure 1 Market buyers (share of volume of emissions reductions purchased)

Source: Lecocq and Capoor (2003).

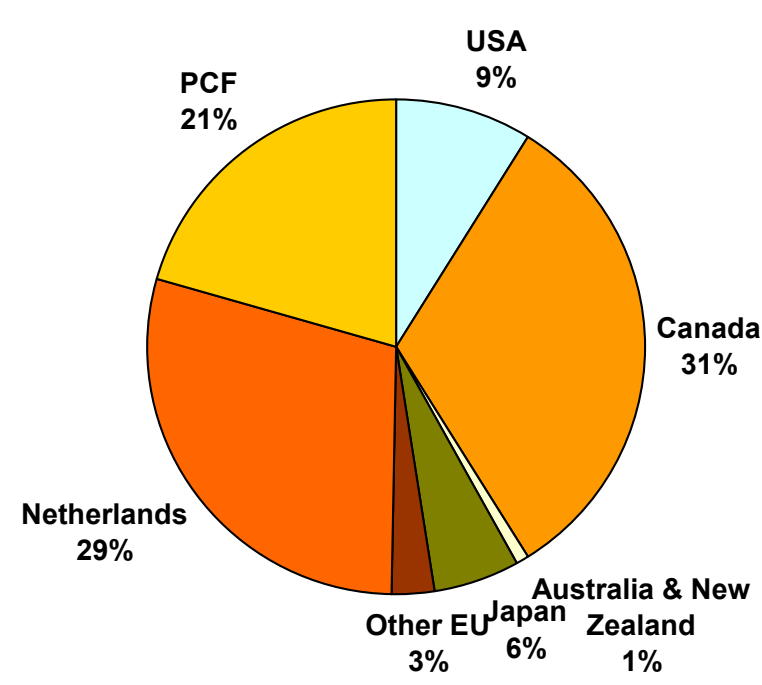

2001-2002

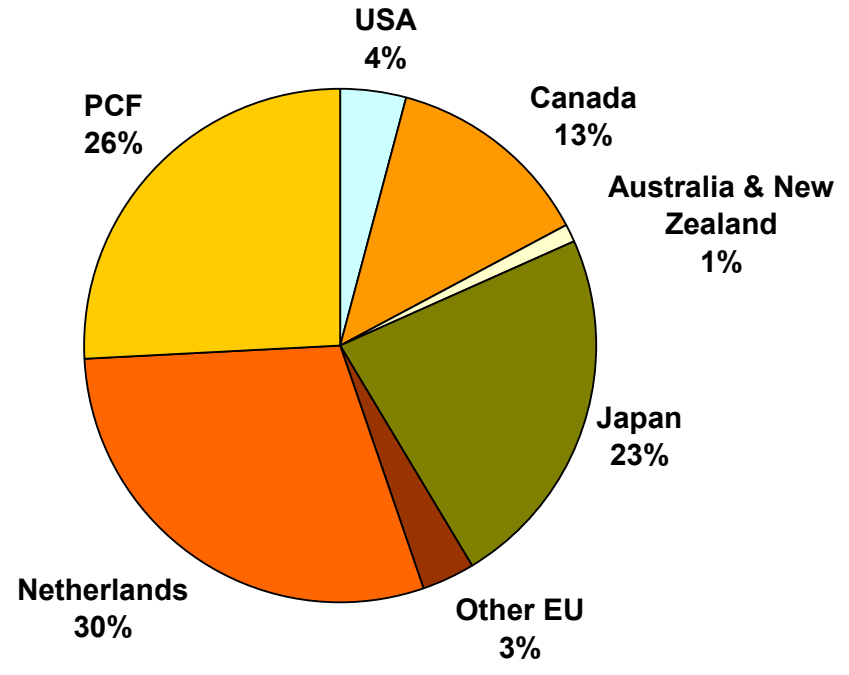

2002-2003

Figure 2 Technology share of emission reduction projects 2002-2003 (in percentage of total volume contracted)

Source: Lecocq and Capoor (2003).

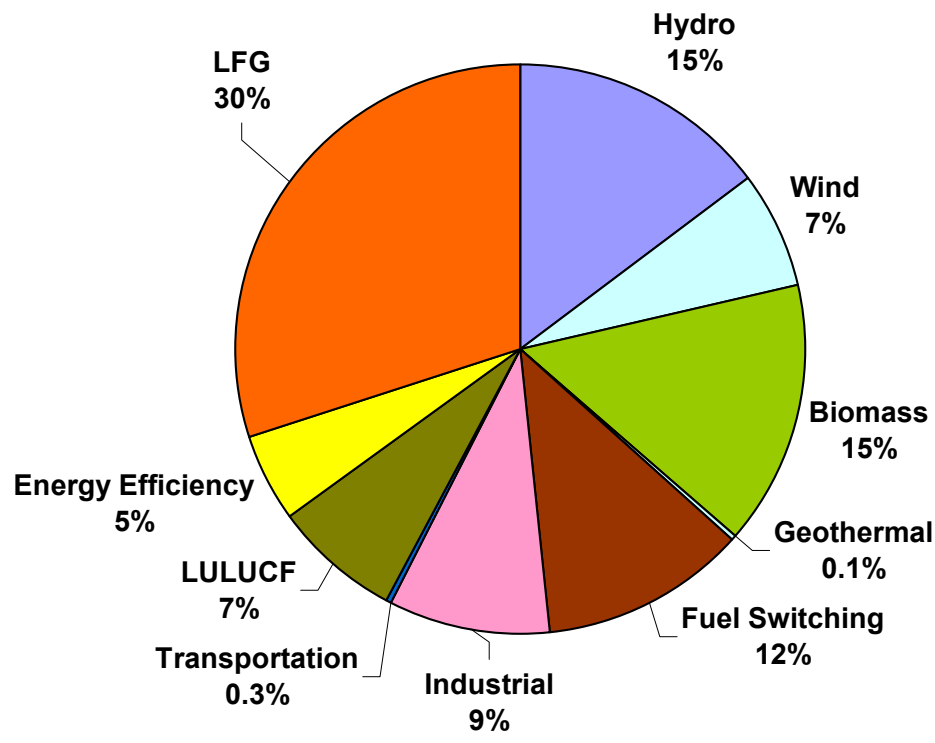


Table 4 The maximum offering prices of CERs under the Dutch CERUPT program

\begin{tabular}{l|c}
\hline CDM project type & $\begin{array}{l}\text { Maximum offering prices of CERs under } \\
\text { the Dutch CERUPT program (€ per ton of } \\
\text { CO } 2 \text {-equivalent) }\end{array}$ \\
\hline Renewable energy (excluding biomass) & 5.5 \\
Biomass energy (excluding waste) & 4.4 \\
Energy efficiency improvement & 4.4 \\
Fossil fuel switch and methane recovery & 3.3 \\
\hline
\end{tabular}

Source: Senter Internationaal (2001).

From the preceding discussion, it thus follows that, to promote the sustainability and expansion of the World Bank's carbon finance initiatives (including the PCF) as an integral part of the Bank's mission to reduce poverty, mobilize resources for carbon financing, and to build the global carbon market over the long run, China and the World Bank should work together on the price issue. It is in their interests. The World Bank is there to promote and demonstrate how the market can work and to help catalyze the carbon market. However, the current, low price levels of CERs would have led its borrowing clients either to spend too much time on negotiations on this or to approve few CDM project proposals than what would otherwise have been the case. Thus, the Bank has an obligation to react to this concern of its borrowing clients as well as that of its lending clients. In the meantime, joining the Host Country Committee of the PCF, ${ }^{15}$ China is now able to play a more proactive role in either pushing for PCF projects at a more favourable price or demanding that the offering prices are differentiated according

${ }^{15}$ A host country of the PCF projects is entitled to be a member of the Host Country Committee if it has signed a memorandum of understanding or a letter of endorsement with the PCF. Membership of the Host Country Committee has grown from less than 15 in the first year of PCF operations to over 50 now (PCF, 2003). 
to technology types. ${ }^{16}$ This will broaden project types that carbon finance renders viable. After all, the PCF transactions, although they are significant in comparison with the current carbon market, account for only few percentages of the total projected emissions reductions required for Annex I countries to meet their Kyoto targets. Much work remains ahead to stimulate both demand and supply so as to progressively scale up project-based carbon transactions and create the necessary liquidity in the global carbon market.

\section{Acknowledgments}

This paper has benefited from useful discussions with the colleagues at the National Development and Reform Commission, Beijing, China and the Ministry of Science and Technology, Beijing, China. That said, the views expressed here are those of the author. The author bears sole responsibility for any errors and omissions that may remain.

\section{References}

Joint Implementation Quarterly (JIQ, 2004), CDM Methodologies Approval Status, JIQ, Vol. 10, No. 1, p.14.

\footnotetext{
${ }^{16}$ As shown in Table 4, the offering prices of CERs under the Dutch CERUPT program are differentiated according to technology types. Renewable energy projects in general have been assigned with a premium price.
} 
Lecocq, F. (2003), Pioneering Transactions, Catalyzing Markets, and Building Capacity: The Prototype Carbon Fund Contributions to Climate Policies, American Journal of Agricultural Economics, Vol. 85, No. 3, pp. 703-707.

Lecocq, F. and K. Capoor (2003), State and Trends of the Carbon Market 2003, December 1, Prototype Carbon Fund, The World Bank, Washington, DC.

Prototype Carbon Fund (PCF, 2002), Impact of Carbon Finance on Project Financing, April 17, The World Bank, Washington, DC.

Prototype Carbon Fund (PCF, 2003), Annual Report 2003, The World Bank, Washington, DC.

Senter Internationaal (2001), Terms of Reference: CERUPT 2001, November 1, The Hague, Available at: http://www.senter.nl/sites/erupt/contents/i000008/tor_cerupt2001.doc.

Zhang, Z.X. (1999), Estimating the Size of the Potential Market for All Three Flexibility Mechanisms under the Kyoto Protocol, Prepared for the Asian Development Bank under Contract TA-5592-REG, Faculty of Law and Faculty of Economics, University of Groningen, The Netherlands.

Zhang, Z.X. (2000), Estimating the Size of the Potential Market for the Kyoto Flexibility Mechanisms, Weltwirtschaftliches Archiv - Review of World Economics, Vol. 136, No. 3, pp. 491-521.

Zhang, Z.X. (2001), An Assessment of the EU Proposal for Ceilings on the Use of Kyoto Flexibility Mechanisms, Ecological Economics, Vol. 37, No. 1, pp. 53-69. Zhang, Z.X. (2004), Meeting the Kyoto Targets: The Importance of Developing Country Participation, Journal of Policy Modeling, Vol. 26, No. 1, pp. 3-19. 